Article

\title{
Determining Simulation Parameters of Prototype Door Hinge for Correlation between Simulation and Experimental Results in United Nations Economic Commission for Europe Regulation No: 11 Tests
}

\author{
Onur Erol ${ }^{1, *}$ and Hande Güler Özgül ${ }^{2}$ \\ 1 Department of Automotive Engineering, Graduate School of Natural Applied Science, University of Uludag, \\ 16059 Bursa, Turkey \\ 2 Department of Automotive Engineering, Faculty of Engineering, University of Uludag, 16059 Bursa, Turkey; \\ handeguler@uludag.edu.tr \\ * Correspondence: 501625507@ogr.uludag.edu.tr or onurero191@gmail.com
}

Received: 3 February 2019; Accepted: 12 March 2019; Published: 15 March 2019

\begin{abstract}
In this study, the simulation parameters of the door hinge were investigated in the $\mathrm{Z}$ direction to have a correlation between the experimental test and simulation. Tests and simulations were conducted according to the United Nations Economic Commission for Europe Regulation No: 11. The simulation parameters, which are the friction coefficient of contacts, the effect of bush material assignment and effect of production imperfections, were examined respectively by utilizing the implicit solver of Ansys Mechanical Workbench 18 and the force-displacement curves were compared with experimental test results in order to decide the optimal settings of parameters. In a conclusion friction coefficient 0.2 , non-linear bush material and realistic geometry model were considered as the optimal parameter settings for correlated Finite Element Model of the hinge.
\end{abstract}

Keywords: finite element analysis; door hinge; UNECE R11 regulation; correlation parameters

\section{Introduction}

Today in the automotive industry, the most important targets are to design accurate, light, cheap and reliable products. Finite element analysis (FEA) is an important design instrument for low prototyping cost and short verification duration. However, FEA's capabilities are based on the quality of correlation between the finite element model (FEM) and the experiment test. Therefore, the literature contains many numerical and experimental verification studies for different products in order to achieve the targets stated above [1].

\subsection{Commercial Door Hinge}

Door hinges are important components that provide links between the door and the vehicle body. The main function of these components is to enable the vehicle door to be opened and/or closed in order to let passengers get into and out of the vehicle. In addition to its main function, it also assures the safety of passengers.

Generally, the door hinges consist of four parts. The fix leaf is the stationary part of the hinge, which is assembled on to the vehicle body. The mobile leaf is the movable part of the hinge, which is assembled on the door. The axis pin assures the link between the mobile leaf and the fix leaf. The bush part which is assembled to mobile leaf and slides on axis pin, assures torque and endurance during operation. Traditionally, these components are produced from steel in various ways such as stamping, and forging. In Figure 1, the components of the door hinge are shown [2]. 


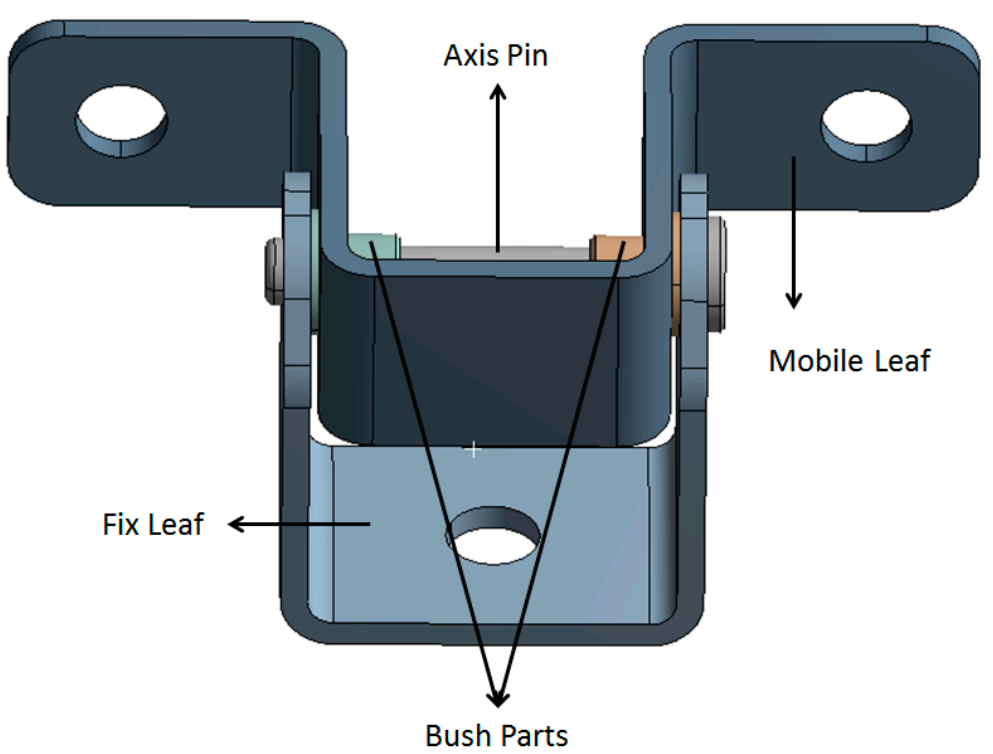

Figure 1. Commercial door hinge.

\subsection{United Nations Economic Commission for Europe (UNECE R11)}

It is justified that one of the vehicle hinge's function is to assure the freight safety of occupants during accidents. Therefore, the customers or regulations (United Nations Economic Commission for Europe Regulation No: 11, Federal Motor Vehicles Safety Standards "FMVSS", Japan Automobile Standards Internationalization Center "JASIC", etc.) demand various validation tests in order to guarantee the strength of the door hinge before the vehicle is put on the market.

UNECE R11 is one of these tests, which is the regulation of the United Nations Economic Commission for Europe.

\subsubsection{Aim and Scope of Regulation}

UNECE R11 is the general product specification that aims to standardize the minimum strength of the door retention components (door hinges, door latches, and etc.) in order to reduce the risk of passengers being thrown from the vehicle during a crash. This regulation contains M1 and N1 type vehicles. M1 type vehicles are used for carrying passengers and the capacity of these vehicles is a maximum of 9 people (including the driver). N1 type vehicles are used for carrying goods and capacity of the vehicle is no more than 3.5 tons [3].

\subsubsection{Regulation Procedure and Acceptance Criteria}

The UNECE R11 regulation examines the strength of the door hinge with experimental tests which are longitudinal loading (11,000 $\mathrm{N}$ in the $\mathrm{X}$ direction of vehicle), Transversal Loading ( $9000 \mathrm{~N}$ in the $\mathrm{Y}$ direction of vehicle), and Vertical Loading (9000 $\mathrm{N}$ in the $\mathrm{Z}$ direction of vehicle) with respect to the coordinate system of the vehicle in Figure 2 [3].

The hinge system must be attached to the mounting provision of the test fixture. The position of the hinges must simulate the door in a fully closed position relative to the hinge centerline. Loads must be applied to the centerline of the hinge pin with respect to the regulation directions. Loading rates must not exceed $5 \mathrm{~mm} / \mathrm{min}$ [3].

The tests must be conducted until the required loads achieved. Separation of each hinge before reaching the required loads is considered as a failure according to the regulation. 


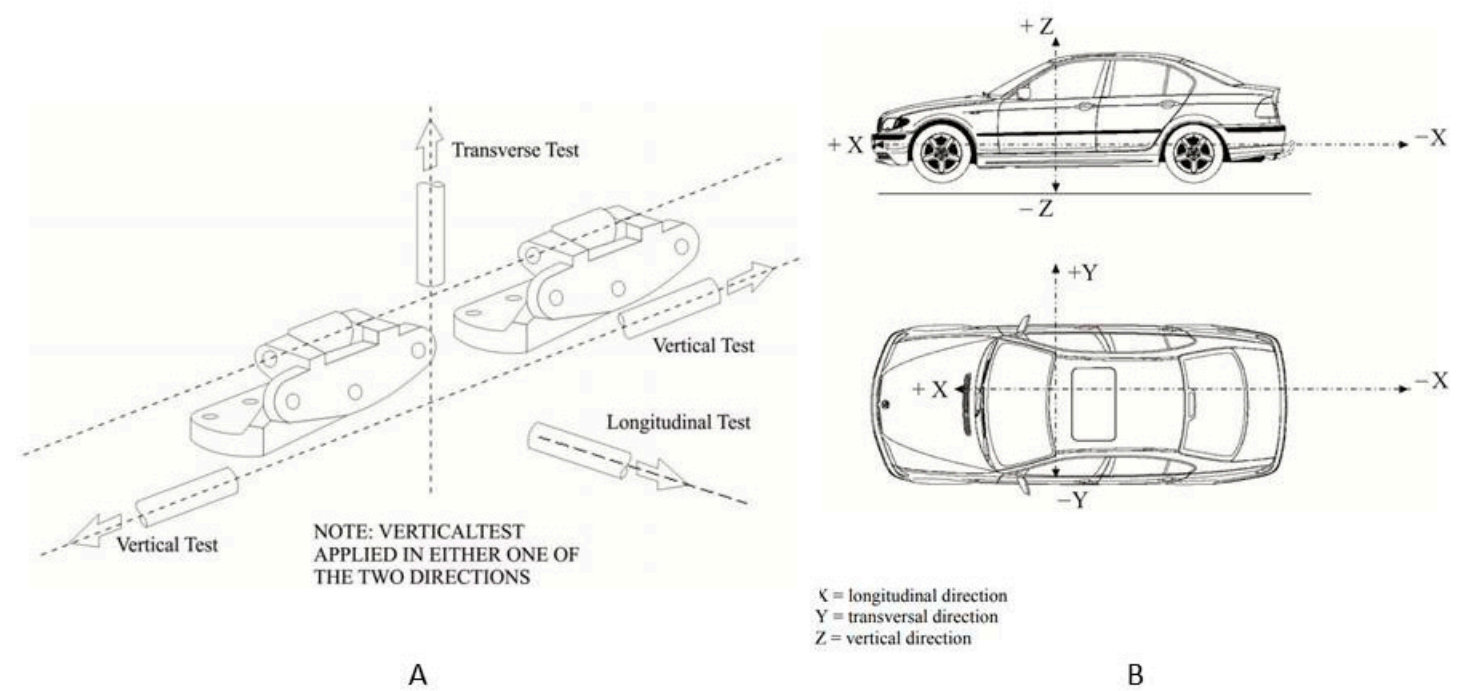

Figure 2. Loading directions of United Nations Economic Commission for Europe (UNECE) R11 ((A) loading directions according to vehicle coordinate system on door hinge, (B) loading directions according to vehicle coordinate system).

\subsubsection{Static Test Apparatus}

The length of the test apparatus must be $406 \pm 5 \mathrm{~mm}$ between extreme ends of the hinges. In addition, the single hinge evaluation also could be conducted, if the hinge set is symmetrical on the vehicle door. However, forces of experimental tests must respect $50 \%$ less than indicated loadings in the regulation. The dimensions of the test apparatus are given for the hinge set and single hinge in Figure 3 [3].

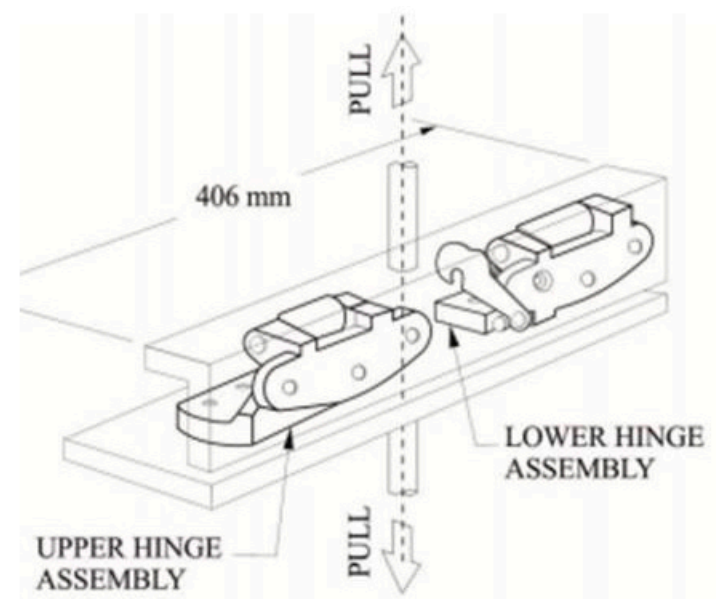

DOOR HINGE SYSTEM

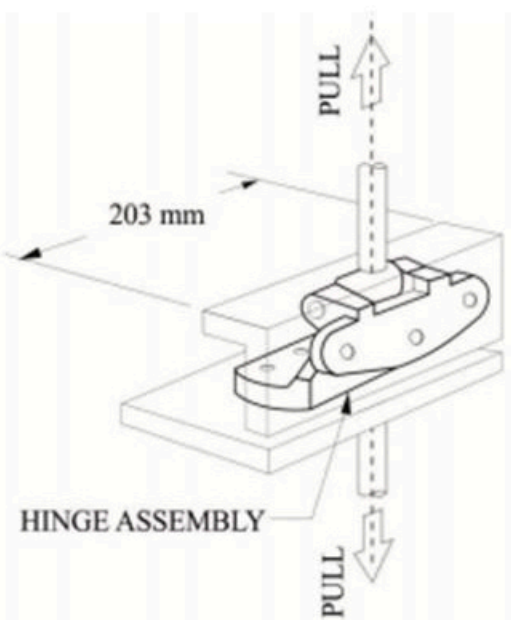

DOOR HINGE

B

Figure 3. The dimensions of the experimental test apparatus ((A) test apparatus for hinge system evaluation, (B) test apparatus for single hinge evaluation). 


\subsection{Literature Study}

There are several design activities in the literature that use the FEA approach of which Dogan et al. shared detailed information about the structural tests for vehicle hinge design. In their study, they conducted a hinge-stretching test, which is a test that is based on FMVSS Regulation No.206 (which is the equivalent standard to UNECE R11), they investigated the correlation results between the FEM and experimental test results [1]. More et al. investigated the design of lateral door hinge according to FMVSS No.206 and Indian standard (IS): 14225 (Indian Motor Vehicle Standard) which are equivalent standards to UNECE R11. They conducted an FEA study, checked stress and deformation results of hinge design in order to decide the optimal model. After the experimental tests to investigate their FEM accuracy and design validation, they shared correlation results [2]. Tufekci et al. investigated optimal hinge design for wind gust conditions. In their study, they utilized FEA to evaluate the initial hinge design. Afterwards, the improved design was investigated again due to the failure of the initial design and the correlation results were shared between the new design and experimental tests [4]. Tufekci et al. investigated the link part of the back door hinge component with a durability test. For their study, they used FEA and topology optimization during the design phase. They shared the results of experimental tests and compared results with FEA. As a conclusion, the product was validated with $60 \%$ of weight reduction at their study [5]. Y1lmaz et al. conducted a design study in order to replace aluminum with steel to have lightweight design. In this study, FEA was used for loading of the hinge according to FMVSS No.206 standard, then FEA results were compared with experimental tests [6]. Bayraktar et al. investigated fatigue strength of the furniture hinge and suggested a new methodology, which provides fatigue analysis of the transient response of the whole structure [7]. Toan et al. investigated a methodology that utilizes the FEA and Taguchi method together in order to improve the stamping performance of vehicle hinges. They improved the stamping performance of one example by changing the radius and other dimensions on the hinge [8]. Darwish et al. investigated a vehicle door in their study. They calculated stress results on components by modal and static analysis. It was stated that the highest stress results on the system are on hinges and consequently employed a number of hinges to reduce maximum stress results and increase modal frequencies and stiffness of the system [9].

\subsection{Motivation and Objective}

In the literature, various studies have been shared about the FEM on the vehicle door opening system. However, the effect of simulation parameters on the force-displacement curves is an important subject, which is unstudied in the literature. In this study, the friction coefficient, geometrical differences, and bush material effects are inspected. These investigations are conducted on the $\mathrm{Z}$ direction loading of UNECE R11 regulation. Authors have chosen the $Z$ direction of loading because this direction is a severe case due to long distance sliding and deformations. In addition, the authors have studied on the hinge, with 2 fixation points was used unlike the literature focus of study. Therefore, sliding on assembly surfaces was inspected in this study in order to add this information to the literature.

The aim of the study is to help the engineers in the automotive industry to correlate quickly and provide researchers a reference model, which can be used in their study with different variations.

\section{Materials and Methods}

\subsection{Dummy Model Design and Production}

Product design is a process that leads from the idea to the new product. Nowadays, engineers use various tools during this process. In this study, Catia V5 R22 is utilized as design software at the first stage and Ansys Workbench 18 is utilized for simulations. 
The aim of the dummy model is to avoid the production imperfections such as increase on material properties due to strain hardening during the forming process, asymmetrical geometry due to the un-uniform forming process, etc. That comes from production. The dimensions of the dummy model are presented in Figures 4-7.
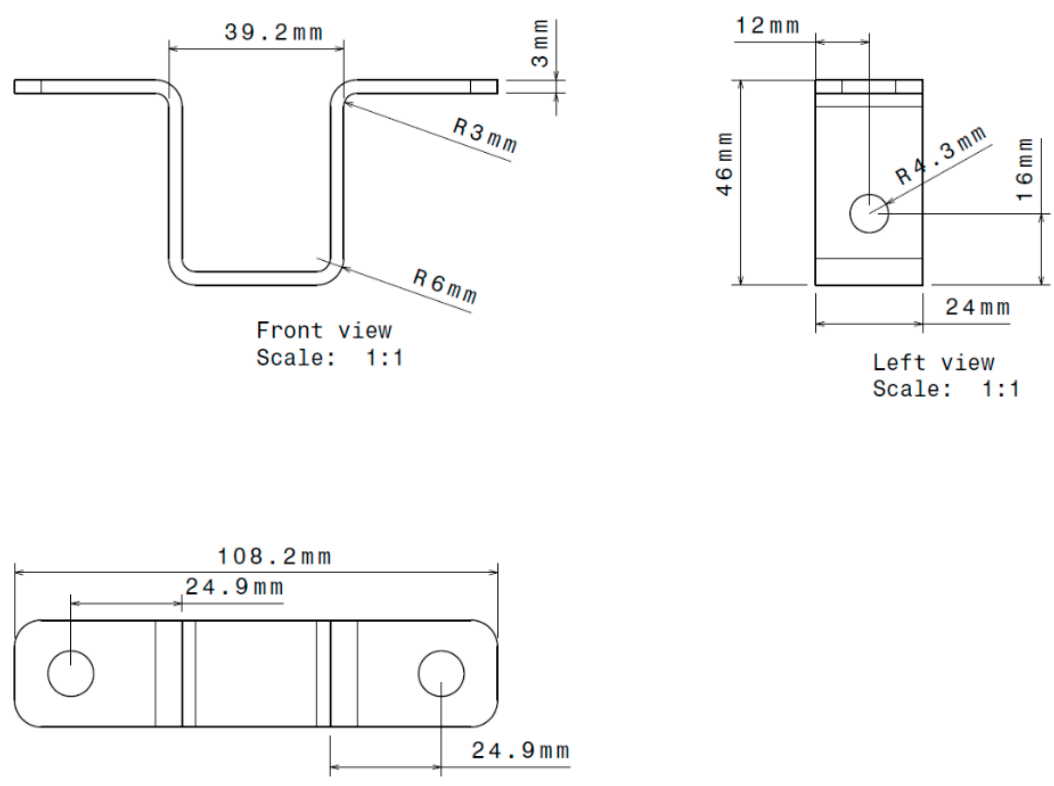

Top view

Scale: $1: 1$

Figure 4. The Dimensions of the Mobile Leaf.
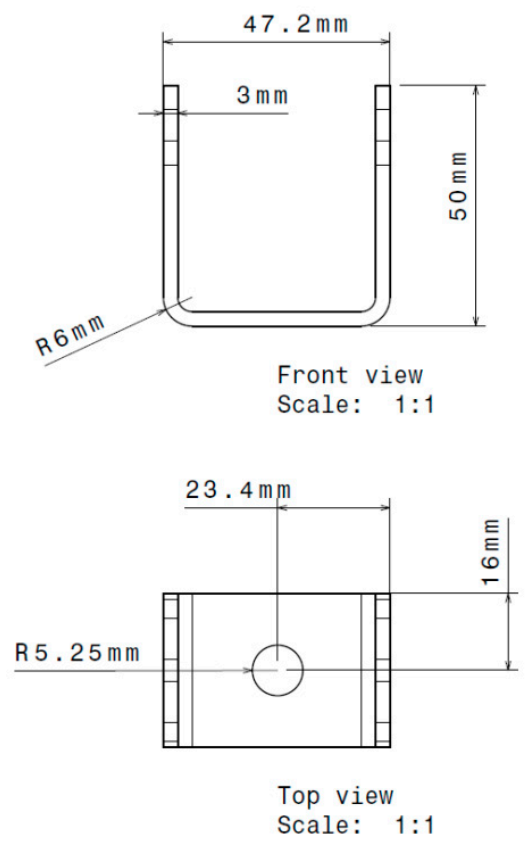

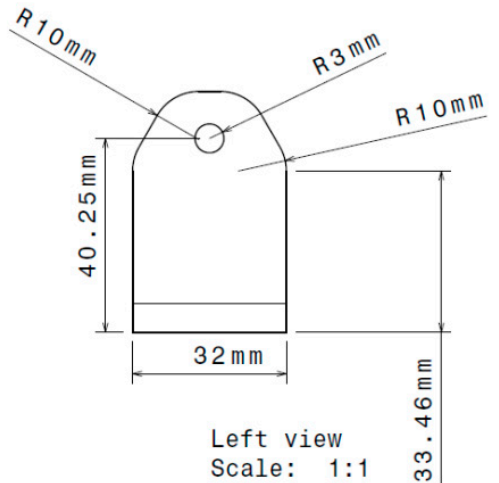

Scale: $1: 1$ लें

Figure 5. The dimensions of the fix leaf. 

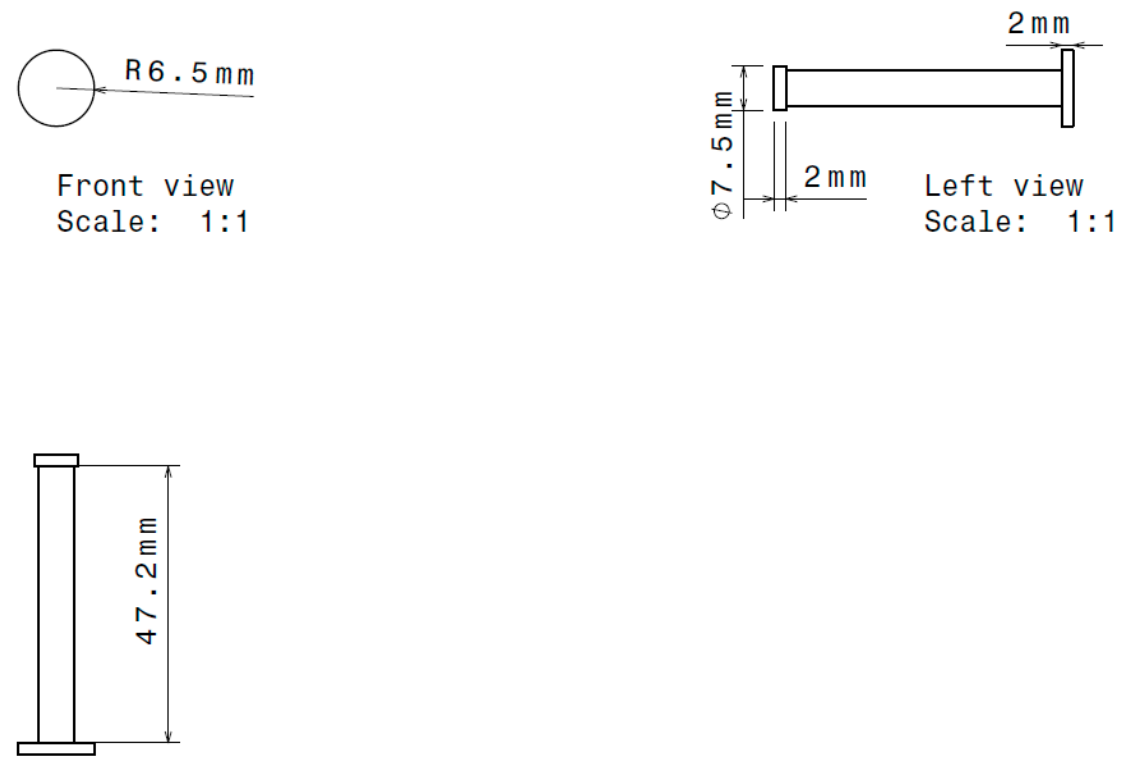

Top view

Scale: 1:1

Figure 6. The dimensions of the axis pin.

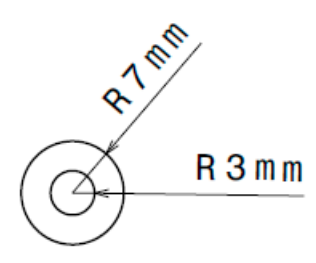

Front view

Scale: $1: 1$

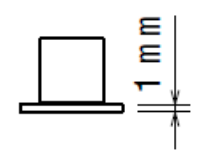

Top view

Scale: $1: 1$

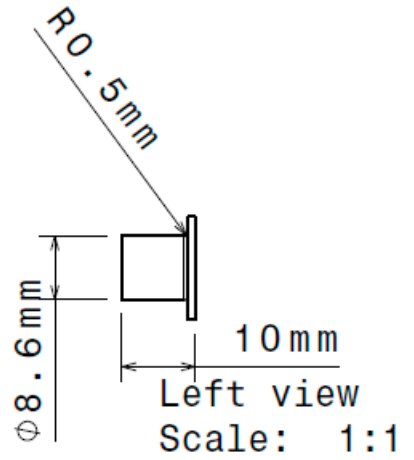

Figure 7. The dimensions of the bush part.

Stamping is a process that is undertaken by placing a sheet blank between die surfaces in order to get it into shape. In this study, prototype stamping tools are used for fix leaf and mobile leaf in Figure 8 , the axis pin was produced through cold forging, and the bush was produced by metal powder technology. 


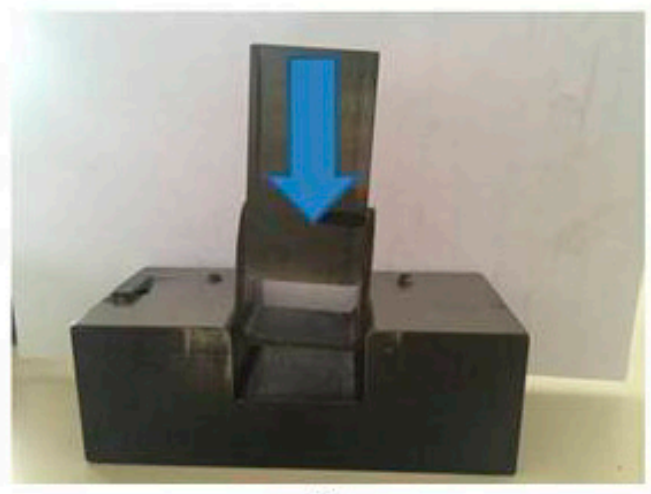

A

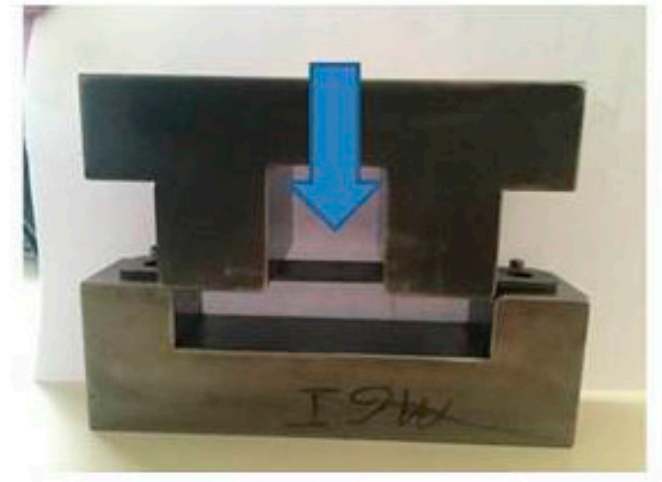

B

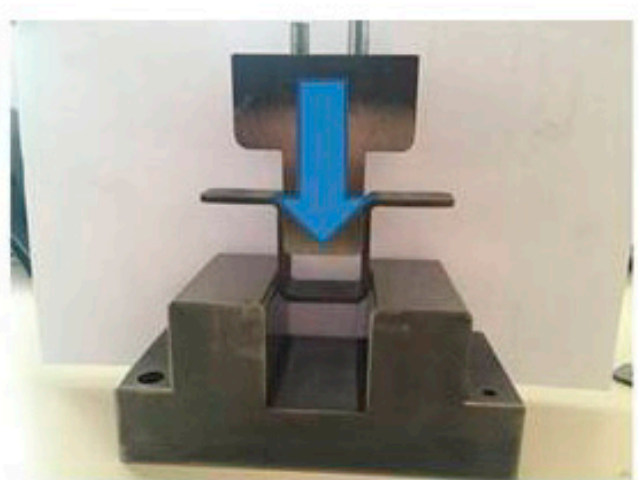

C

Figure 8. Prototyping steps of dummy door hinge ((A) bending operation of fix leaf, (B) first bending operation of mobile leaf for assembly surfaces, (C) final bending operation of mobile leaf).

\subsection{Material Data}

Material properties are among the important inputs in FEA. The unrealistic tensile curves of materials affect the deformation results of FEA, therefore FEA may differ from experimental tests. These unrealistic results may affect the judgment of the analyst. In this study, material assignments are indicated for each component in Figure 9.

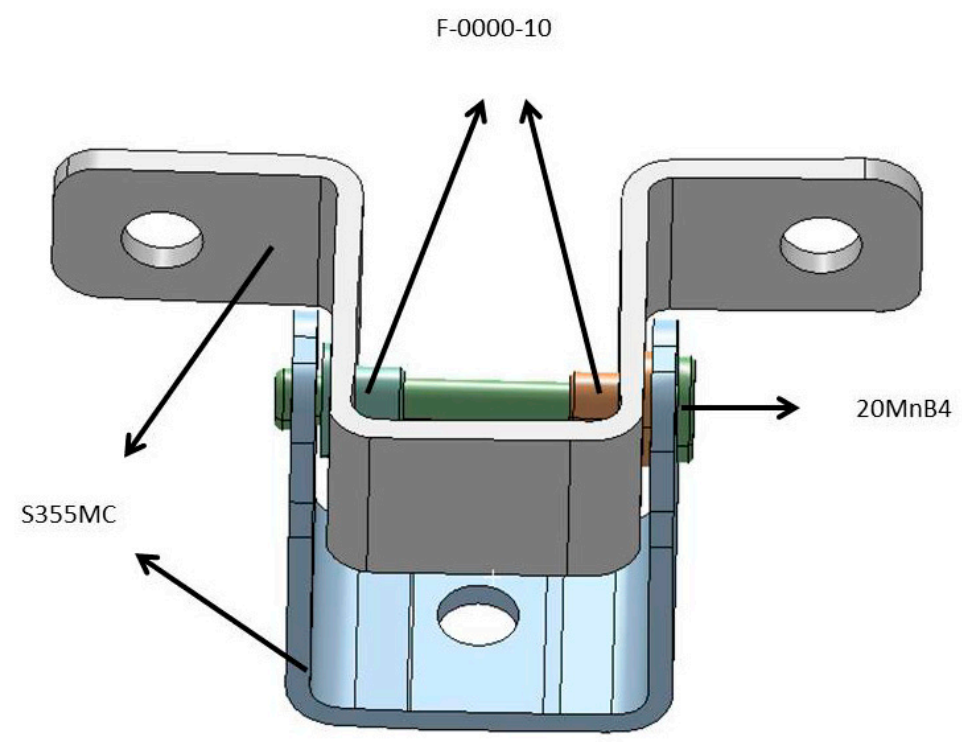

Figure 9. Material assignment for the components. 
In this study, the tensile test was conducted on S355MC according to the American Society for Testing and Materials (ASTM) E8/E8M standard and the engineering tensile curve was gathered. The material tensile curve of the axis pin is searched for in the literature and information is gathered [10]. Material properties of F-0000-10 are gathered from the metal powder industry standard 35-SP [11].

In order to gather the tensile curve of the S355MC, dog bone tensile test samples are created. The sample model with $12.5 \mathrm{~mm}$ was chosen due to its compatibility with the gripping section of the tensile test machine. The test was conducted under $5 \mathrm{~mm} / \mathrm{min}$ of tensile speed.

After the tensile test was undertaken, the engineering curve and other material data were converted into true stress-strain states with the formulas in Equations (1) and (2) [12].

$$
\begin{gathered}
\sigma \text { true }=\sigma \text { engineering }{ }^{*}(1+\varepsilon \text { engineering }) \\
\varepsilon \text { true }=\ln (1+\varepsilon \text { engineering })
\end{gathered}
$$

In this study, excessive deformations were expected on the dummy hinge. Therefore, the true tensile properties of the materials are used. The material curves were shown in Table 1 and Figure 10a-c.

Table 1. Material properties for finite element analysis (FEA).

\begin{tabular}{cccccc}
\hline Material Name & $\begin{array}{c}\text { FEA Material } \\
\text { Models }\end{array}$ & $\begin{array}{c}\text { Elasticity Modulus } \\
\mathbf{( M P a )}\end{array}$ & $\begin{array}{c}\text { Yield Stress } \\
\mathbf{( M P a}\end{array}$ & $\begin{array}{c}\text { Rupture Stress } \\
\mathbf{( M P a )}\end{array}$ & $\begin{array}{c}\text { Elongation } \\
\mathbf{( \% )}\end{array}$ \\
\hline Steel & Isotropic Linear & 200,000 & No Plasticity & No Limit & No Limit \\
F-0000-10 & Isotropic Non-linear & 96,500 & 89.6 & 124 & 0.02 \\
S355MC & Isotropic Non-Linear & 194,300 & 434.95 & 611.07 & 0.14 \\
20MnB4 & Isotropic Non-Linear & 200,000 & 403.05 & 636.04 & 0.1486 \\
\hline
\end{tabular}

\subsection{Finite Element Model (FEM)}

\subsubsection{Simulation Parameters for Evaluation}

Finite element analysis is a reliable tool for the design process of the product. It reduces the time needed for design and validation processes. Simulation tools have several advantages such as analyzing complex geometry, anisotropic and non-linear material, etc. The accuracy of the simulation results depends on the real material properties of the product, proper boundary conditions, and sufficient mesh [6].

The aim of the study is to determine the FEA parameters that affect the simulation results in order to correlate with experimental test results. Therefore, the geometrical difference between geometrical data and dummy door hinge, the friction coefficient of contact definition at moving parts and bush material effects were chosen for evaluation. In order to evaluate the effect of parameters individually, one parameter is changed at a time during the study.

\section{Geometrical Difference}

At the beginning of the study, the idea of the dummy hinge model was to have a hinge, which has as few imperfections as possible thanks to its production. Therefore, test samples were investigated under 3D scanning. Figure 11 shows the scan results. The investigation was conducted with Atros core optical 3D scanner and GOM inspect 2017 software. 


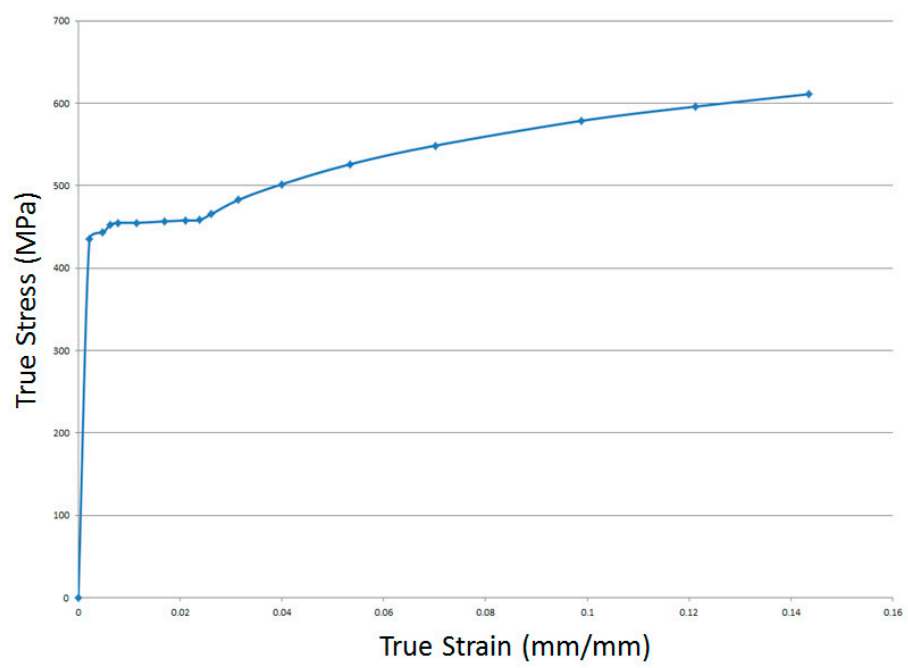

(a)

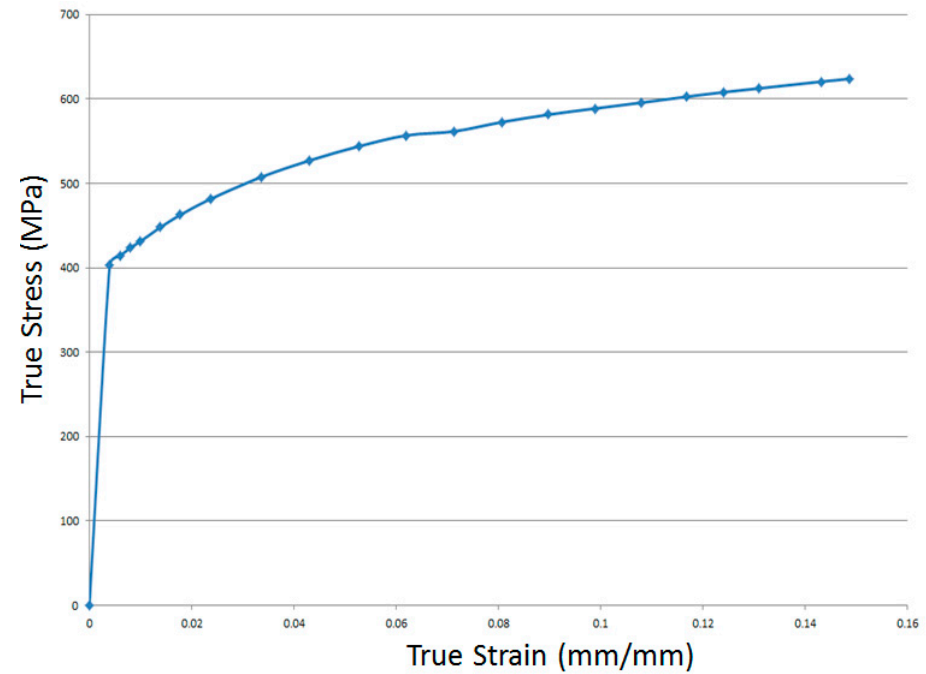

(b)

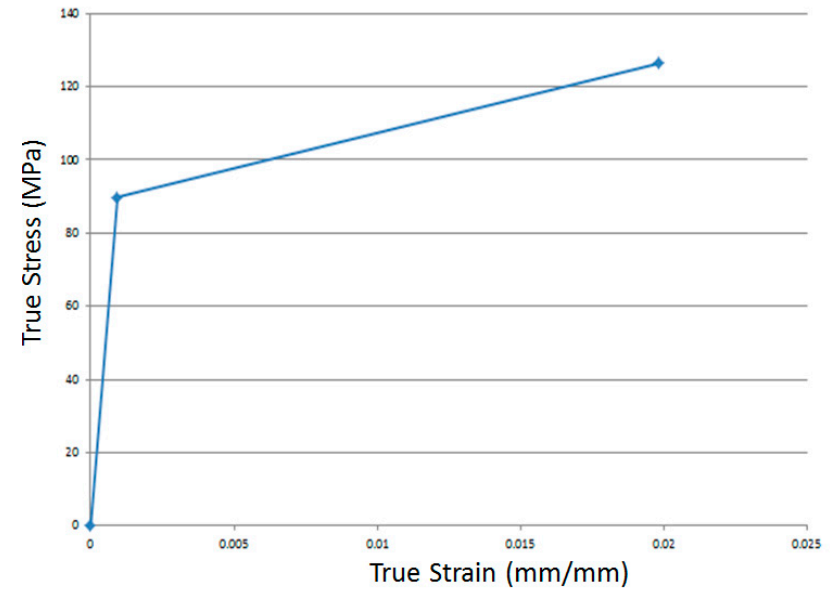

(c)

Figure 10. (a) True stress-strain curve of S355MC; (b) true stress-strain curve of 20MnB4; (c) true stress-strain curve of F-0000-10. 

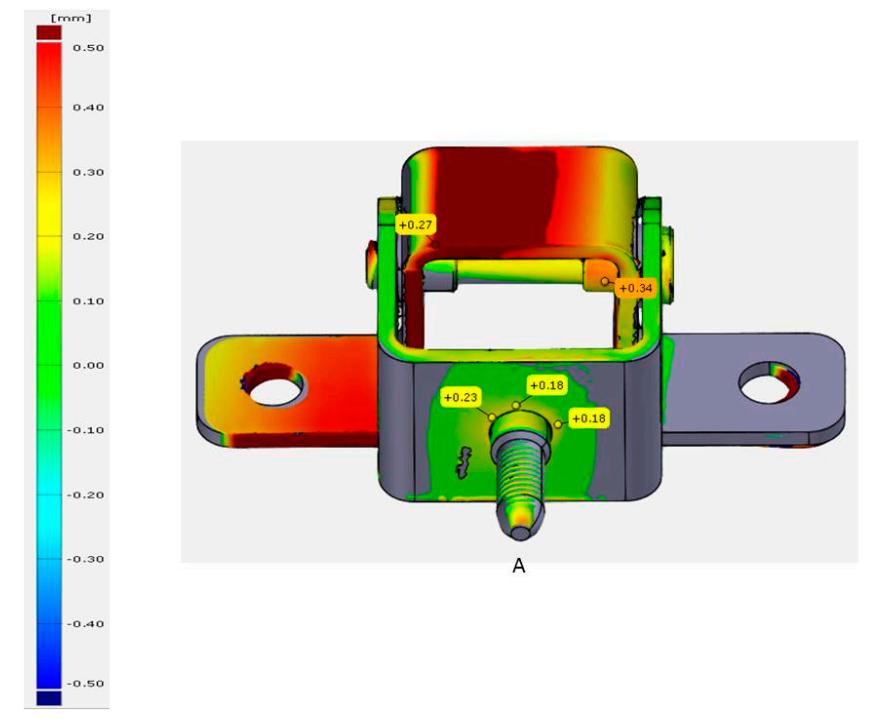

(A)

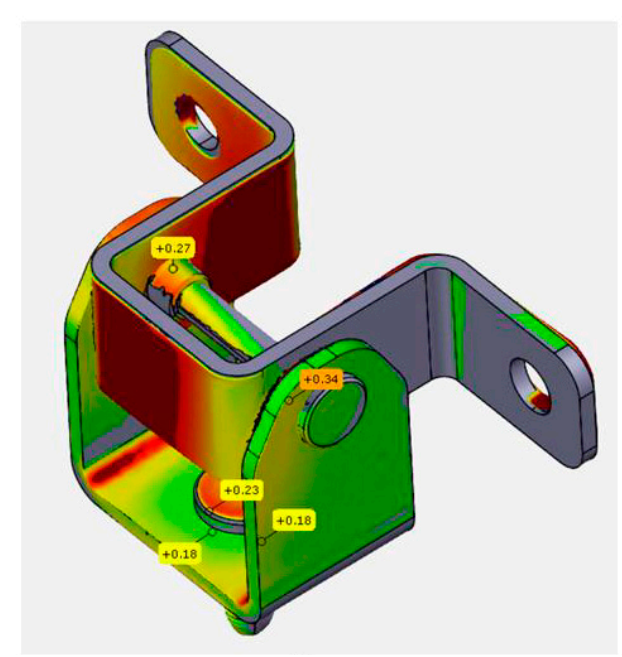

(B)

Figure 11. 3D Scanning results of dummy door hinge ((A): bottom view, (B) right view).

In the plot, colors from green to red colors indicate the distance, which is outside from the reference geometrical data. Colors from green to dark blue indicate the distance, which is inside of reference geometrical data, grey color indicates the reference geometrical data.

The results show that there was a $0.2 \mathrm{~mm}$ difference at the assembly surface of fix leaf between geometrical data and produced dummy hinge. This deviation was observed during the bending process of fix leaf. It was observed that side faces of fix leaf leaned on $0.2 \mathrm{~mm}$ to one side rather than perpendicularly. The riveting process of axis pin was considered as a cause of this difference. The prototype hinge axis showed poor coincident with the axis of geometrical data. Poorly positioned assembly hole of axis pin was considered as the root cause of poor coincidence. In addition, it was observed that the mobile leaf was deformed inside itself. Therefore, the distance between assembly holes got closer as an effect of deformation. This deformation occurs due to the bending process of mobile leaf and poorly positioned assembly holes.

Poor positioning at assembly holes of the axis pin may increase effort results. But it was observed that the hinge could be opened and closed by hand. Therefore, additional effort may not affect test results and it was considered negligible. It was indicated that the deformed areas were observed 
between mobile, fix leaves and test apparatus. These deformations were considered the cause of gap at the assembly surface and these conditions were considered effective on force-displacement curves, because of these deformations are the cause of having insufficient support on its provision. This condition led to less system stiffness than the simulation in experimental tests.

Because the 3D scan was conducted in bolt pretension free conditions, assembly surfaces were also evaluated on test apparatus with a feeler gauge. It was considered that bolt pretension also deforms the fix leaf around the head of the fixing screw in order to close the gap. After being evaluated with the feeler gauge, it was measured as $0.05 \mathrm{~mm}$ with feeler gauge until the screw shaft under bolt pretension in Figure 12. Therefore, 3D scan data was converted to geometrical data by Spaceclaim software respecting the 3D scan and handmade measurement.
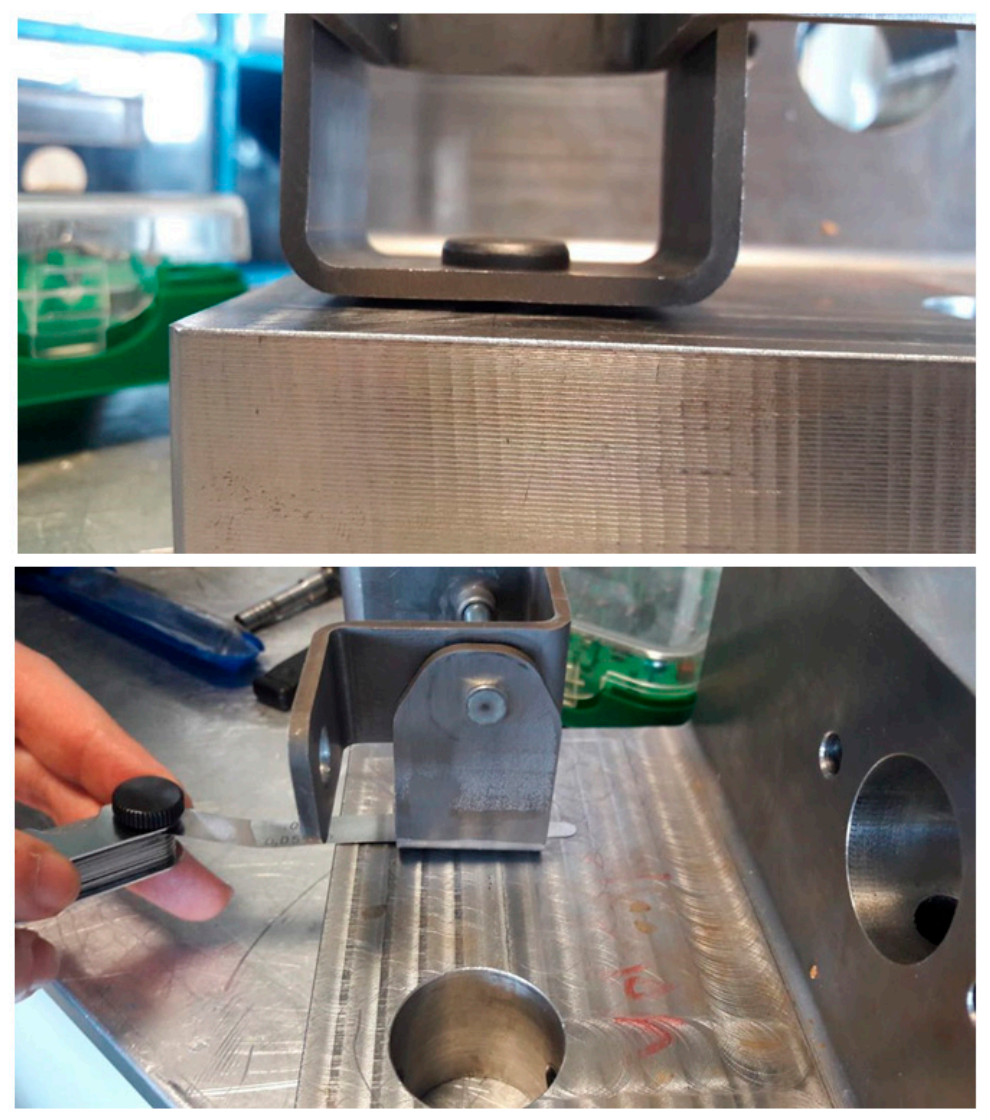

Figure 12. Gap evaluation of dummy door hinge on test apparatus with 0.05 feeler gauge.

\section{Friction Coefficient}

The test sample was subjected in the Z direction under UNECE R11 test conditions. For parameter evaluation, the contacts were chosen as they show sliding during loading. Contacts were shown in Figure 13 and they were evaluated by defining different friction coefficients. In this study, a 0.2 friction coefficient was taken from another study as a reference [5]. Then, different friction coefficients were defined as $0.1,0.05$. These values were determined in order to choose the proper friction coefficient at long distance sliding contacts and frictional forces of the system. 


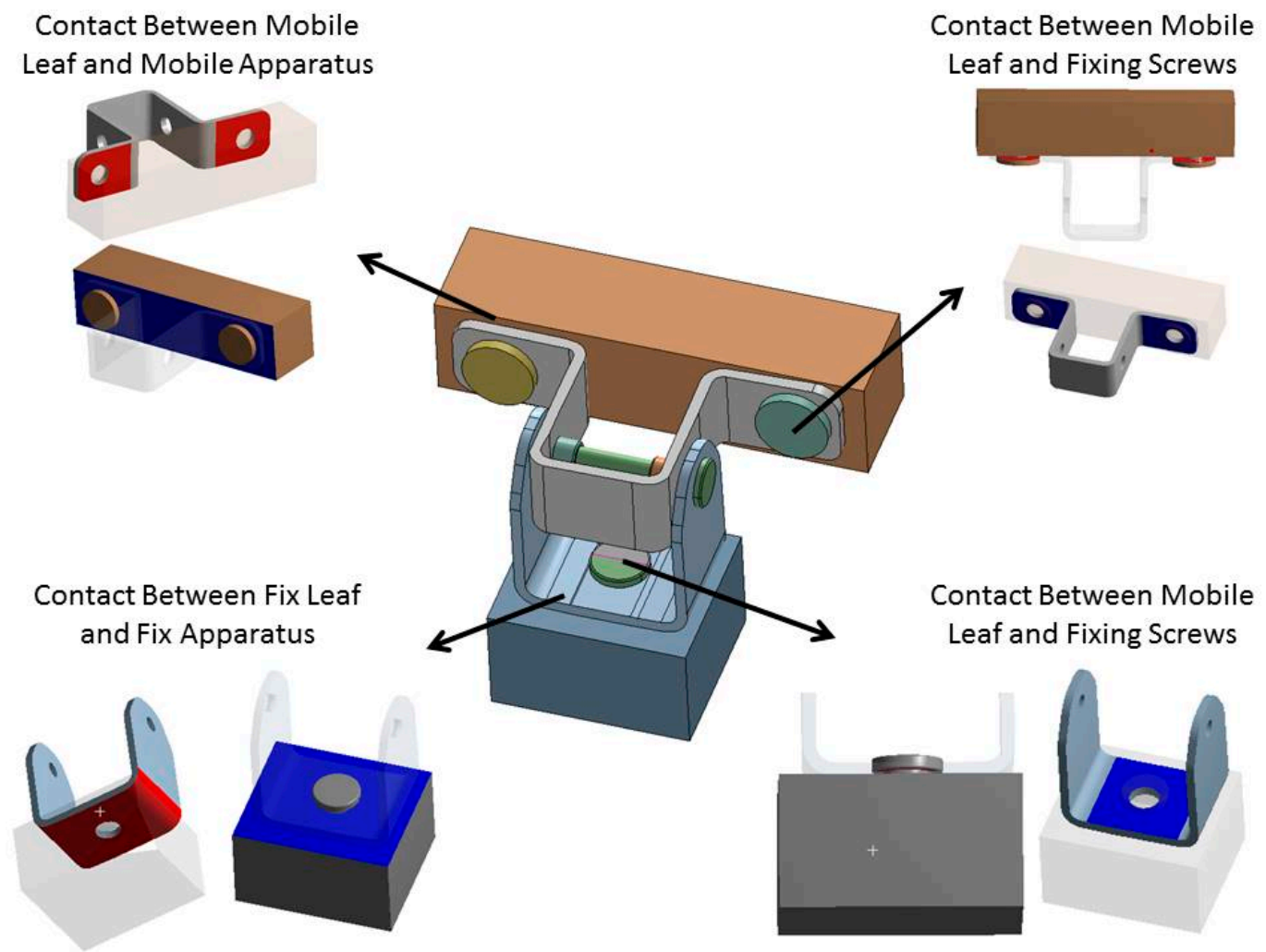

Figure 13. Common contact regions for friction evaluation.

\section{Bush Material Effect}

In the automotive industry, the material properties of bushes are neglected due to their small dimensions and composite structure (steel + teflon, bronze mesh for calibration, etc.). Instead of simulating this complex structure in their system, analysts generally choose to utilize linear structural steel material.

In this study, it was aimed to show the impact of assigning bush material instead of linear structural steel. Therefore, calculations were done with linear structural steel and F-0000-10 separately according to the properties in Table 1.

\subsubsection{Mesh}

Mesh algorithms have vital importance at FE (Finite Element) calculations because analysts introduce geometry that pertains to the product and to analysis tool by meshing. In this process, two parameters affect the accuracy and duration of the analysis directly. These are mesh size and algorithm.

At the beginning of the study, the different mesh sizes and the algorithms were evaluated. No significant effects on the results were observed. Therefore, hex-dominant mesh algorithm was utilized for the mobile leaf, fix leaf, bushes, axis while the tetrahedron mesh algorithm was used for mobile and fix apparatuses. Element sizes of $1.5 \mathrm{~mm}$ were assigned for mobile and fix leaves. In addition, $1 \mathrm{~mm}$ mesh sizing was assigned for bushes, axis pin and fixing screws; $5 \mathrm{~mm}$ mesh size was assigned to the apparatus. This mesh algorithms and sizing were chosen in order to have time efficiency and accuracy with a good representation of geometrical data.

Defined mesh parameters lead the FE model to have 134,730 nodes and 44,601 elements. Mesh element types and element sizes are indicated for each part in Figure 14. 


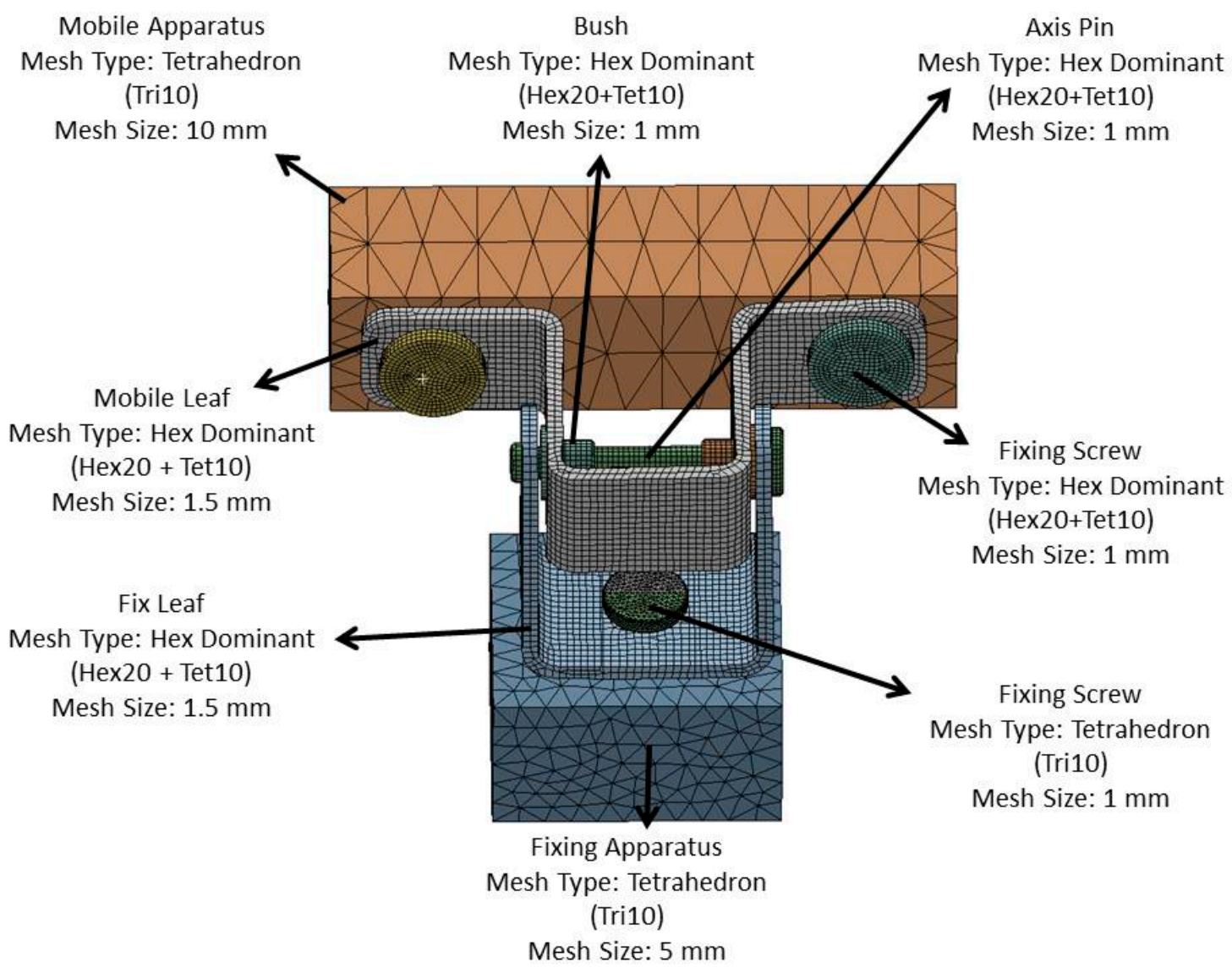

Figure 14. Finite element (FE) mesh properties of the door hinge system.

\subsubsection{Contact Definition}

Contact algorithms define the relationship between parts, which are in touch during calculation. Ansys Finite Element (FE) software provides five types of contact algorithms. These are named as bonded, no separation, frictionless, frictional and rough. Each type states different behavior and these are indicated below;

Bonded: Defined contact pairs work as welded. Sliding and separation are neglected. It is defined as a linear algorithm;

No Separation: Sliding is allowed between pairs. However, they cannot be separate. It is defined as a linear algorithm;

Frictionless Contact: Sliding and separations between contact pairs are allowed. The zero friction value is assumed between contact elements. It is defined as a nonlinear algorithm;

Frictional contact: Sliding and separations between contact pairs are allowed. Users can define friction manually. It is defined as a non-linear algorithm;

Rough contact: Infinite friction value is assumed. Therefore, separation is allowed between pairs. But no sliding occurs [13].

In this study, frictional contact definitions were used as shown in Figure 15. Friction coefficients of the contacts were defined according to simulation parameter inspection. A pure penalty was chosen for the contact algorithm to have short calculation time and the contact stiffness was chosen as 0.6 with a condition of updating stiffness between iterations. This contact stiffness was chosen in order to avoid convergence issues by keeping the accuracy of the stiffness. 


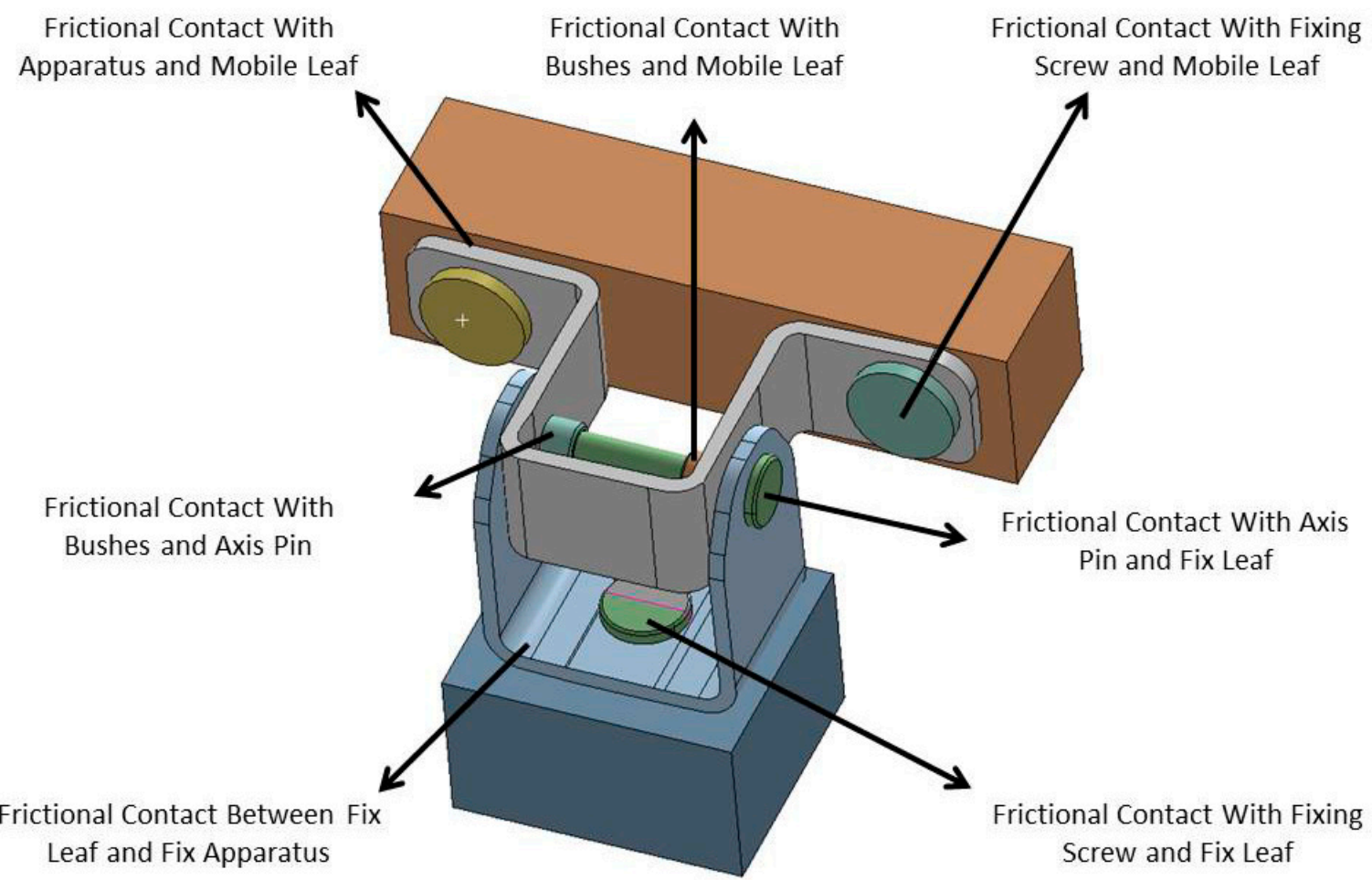

Figure 15. Contact definitions at the FE model.

\subsubsection{Boundary Conditions}

UNECE R11 test contains three different loading in the directions of X, Y and Z. In the scope of this study, the simulations are created in the $\mathrm{Z}$ direction for a single hinge, and force-displacement curves were gathered for examination with experimental tests. The authors decided to use the single hinge approach at the study according to UNECE R11. This approach was chosen to avoid non-uniform imperfections on dummy hinges, which were produced by prototyping.

The loading was applied to the mobile apparatus with the remote point displacement on the apparatus surface, which is different from force-based loading at the literature. The authors have chosen this approach to create such a methodology as was used in the tensile test machine because the tensile test machine applies displacement to the hinges principally in the experimental test. Afterwards, the reaction forces were collected by the load cell during loading. In the simulation, the reaction forces were gathered from the remote point. The fix apparatus has been fixed from the bottom in all directions, and $21 \mathrm{Nm}$ was applied to fixing screws as bolt pretension.

Implicit solver was used on Ansys Workbench 18 for simulations. All calculations were conducted with large deflection effect consideration and default convergence criteria of Ansys mechanical were accepted.

In this study, some assumptions have been used which are neglected in the literature [1,2,4-6]. In the simulations, the loading was applied to the apparatus, not to the mobile leaf's holes. By doing so, the mobile and fix leaves have been freed to rotate around fixing holes against friction force caused by pretension. In addition, the contact definitions between apparatuses and leaves have eliminated unrealistic bending of the assembly surfaces of leaves and unrealistic stresses around fixing holes, and the bolt pretension has been considered in simulations. The boundary conditions are shown in Figure 16. 
Mobile Apparatus

X:Fixed, Y:Fixed, Z: Free, Rx: Fixed, Ry: Fixed, Rz: Fixed

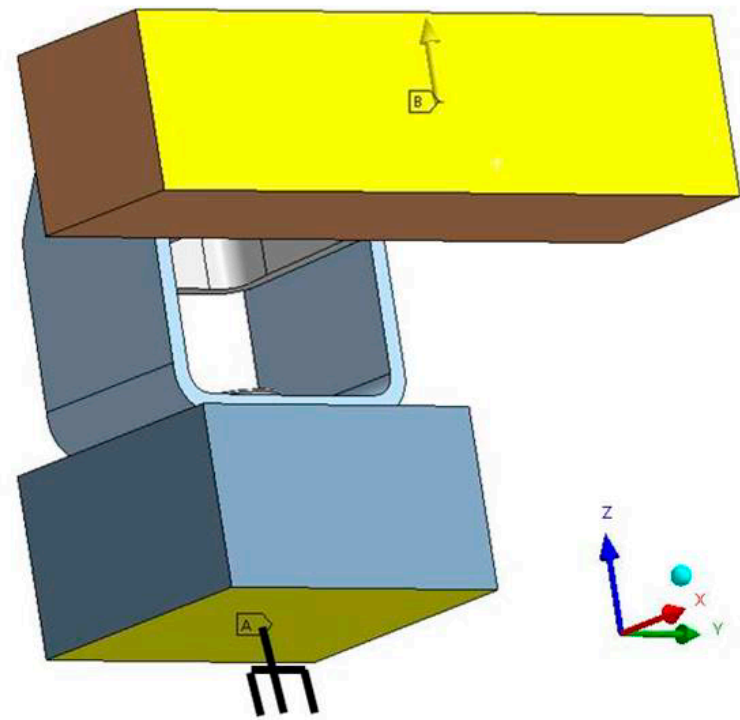

Fix Apparatus

X:Fixed, Y:Fixed, Z: Fixed, Rx: Fixed, Ry: Fixed, Rz: Fixed

Figure 16. Boundary conditions for loading in $\mathrm{Z}$ direction.

\subsection{Experimental Tests}

According to UNECE R11, test apparatuses were designed for the single hinge evaluation, Figure 17. Fixation holes of test apparatuses were designed for the traction machine in compliance with traction through the centerline of the hinge axis to the vertical direction of the vehicle. Test apparatuses were designed as the L-shape with $30 \mathrm{~mm}$ thickness.

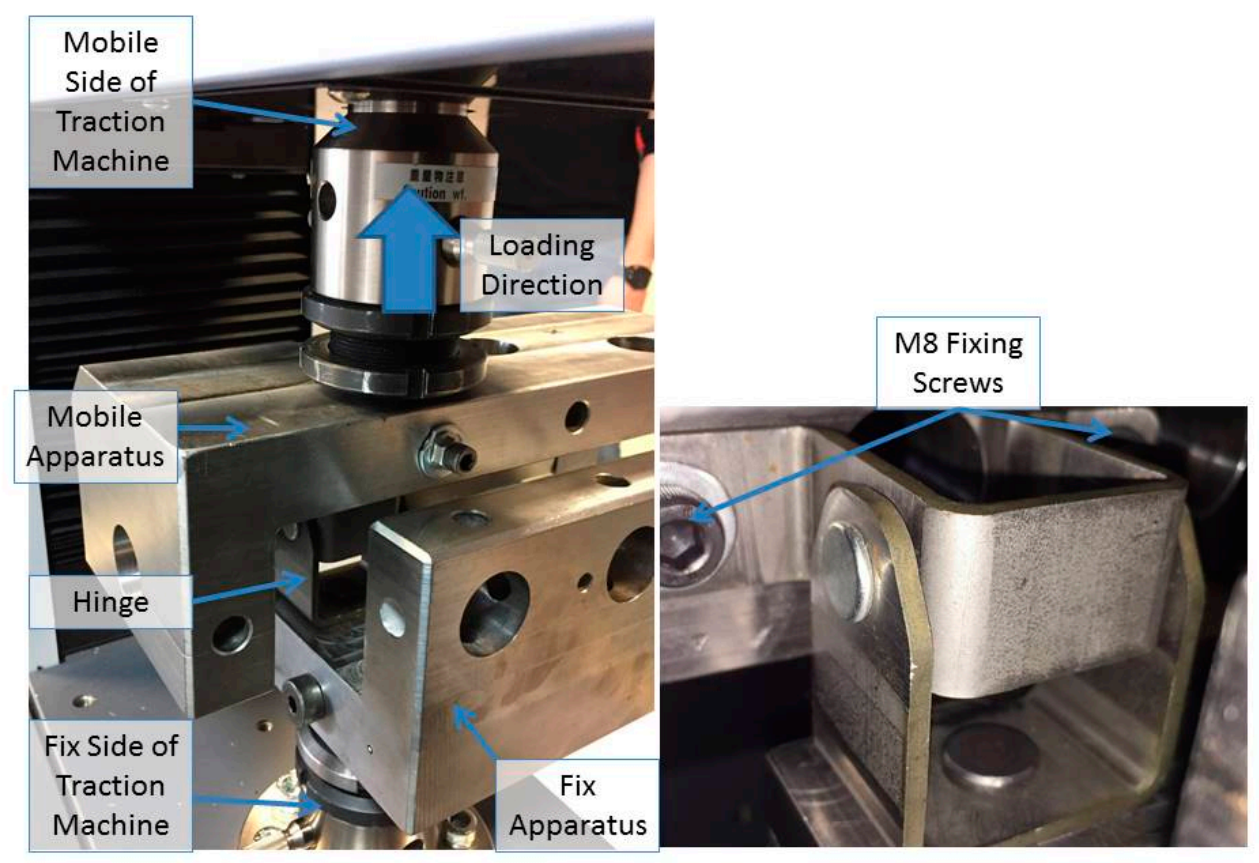

A

B

Figure 17. UNECE 11 test configurations ((A) test setup, (B) hinge appearance on test setup). 
For tests, M8 Class 8.8 screw was chosen for this study. Due to that, it is the most common fastener in the automobile industry, Figure 18; $21 \mathrm{Nm}$ was applied to fixing screws as a pretension.

Shimadzu Autograph AGS-X $50 \mathrm{kN}$ was used as a tensile test machine during tests, Figure 18. The loading was applied as a displacement with a $5 \mathrm{~mm} / \mathrm{min}$ tension rate, and force-displacement curves were gathered by the load cell in Figure 17, which is on the tensile test machine.

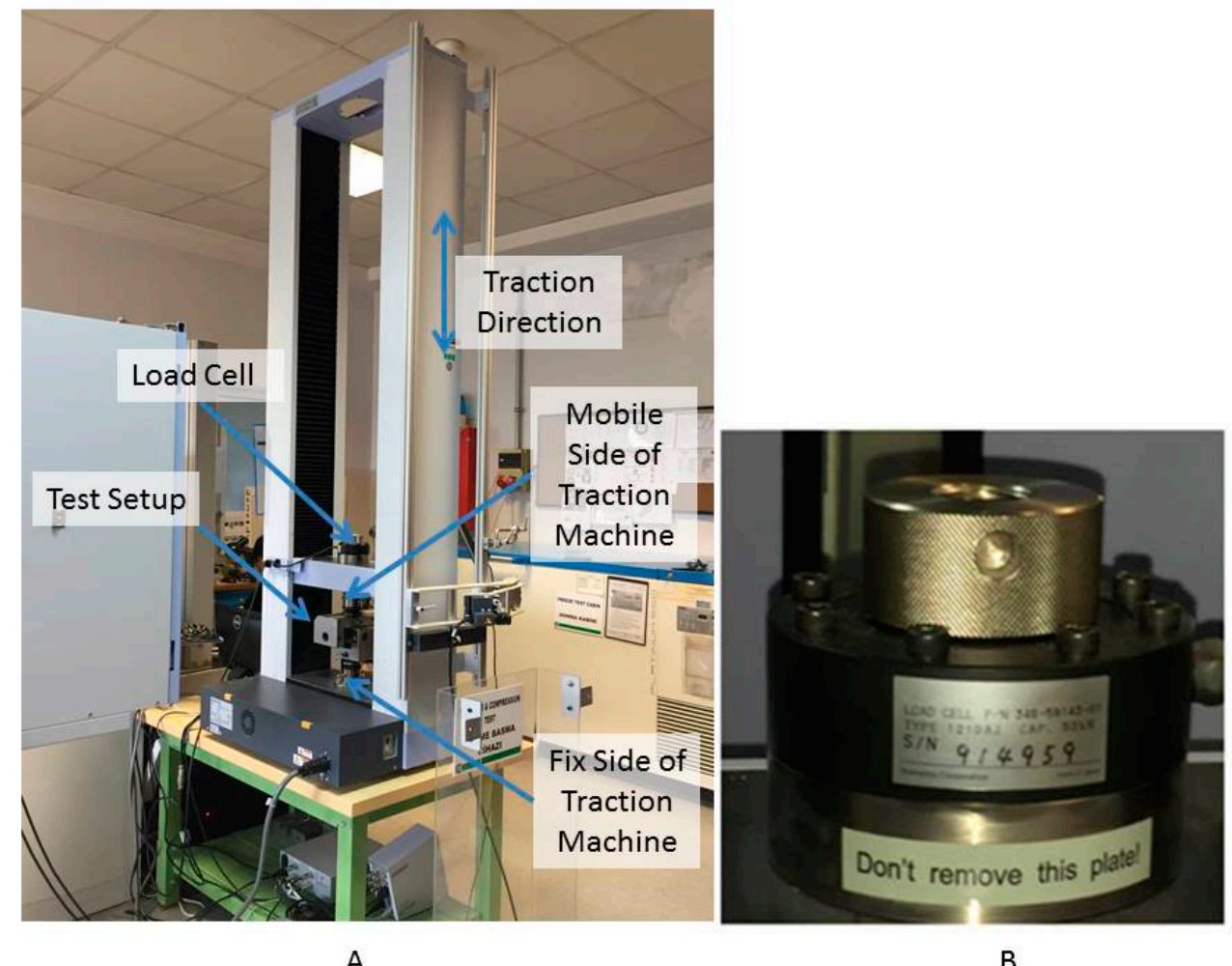

Figure 18. Tensile test machine configurations ((A) tensile test machine, (B) load cell).

The test was conducted with respecting UNECE R11 conditions. Under requirement loadings, no rupture was observed on the hinge components. The test sample shows compliance with UNECE R11 acceptance criteria. Deformation shapes were shared under and after the test in Figure 19.

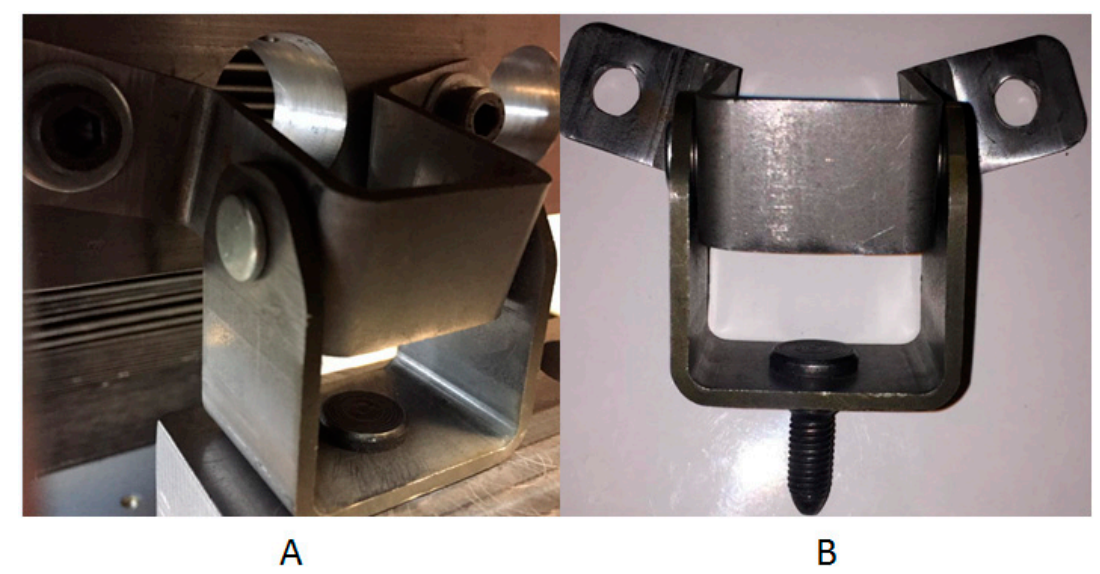

Figure 19. The appearance of test samples ((A) sample appearance under loading, (B) sample appearance after test). 


\section{Results and Discussion}

In this study, the displacement was applied to the dummy hinge according to UNECE11 regulation and force-displacement curves were gathered. Afterwards, error values were calculated between deformation values shown in simulations and experiments, at 4,500 $\mathrm{N}$ according to Equation (3). In addition, the force-displacement curves were inspected to compare the stiffness behavior of the finite element models and the experimental tests.

$$
\text { Error }(\%)=\left(\mid \text { Displacement } \text { Simulation }_{-} \text {Displacement Test } \mid / \text { Displacement Simulation }\right) \times 100
$$

At the beginning of the study, the calculations were conducted with the perfect geometrical data in order to evaluate the effect of the simulation parameters, which are friction coefficient and bush material. Although the error value of $10.57 \%$ was acceptable at $4500 \mathrm{~N}$, the divergence was observed at the force-displacement curves of the simulations with the experimental test. This phase was named as phase-1. Afterward, geometrical imperfections of production were decided to be inspected. Therefore, $3 \mathrm{D}$ scanning was conducted on a dummy hinge and 3D geometrical data were created according to scanning results. This realistic geometrical data was added as a 3rd parameter into the study, and other parameters were calculated with combinations of it. This phase has been called as phase- 2 .

\subsection{Phase-1}

Perfect geometrical data were used for calculations at this phase. One parameter was kept variable in order to see the effect on force-displacement.

\section{Friction Coefficient and Bush Material Effects for Z-Direction Loading}

Force-displacement results were shown for various friction coefficients in Figure 20. It is observed that friction coefficients cause various frictional forces in the hinge system. Therefore, results depend on the friction coefficient. In addition to the same results, it is observed that steel and F-0000-10 have coincident force-displacement curves. Therefore, it is interpreted that bush material has no significant impact on test results.

At all simulation models, force-displacement curves show divergence at the beginning and end with experimental test results. Also, maximum and minimum error values are $32.22 \%, 10.57 \%$ respectively at 4,500 N. Error values are indicated in Table 2.

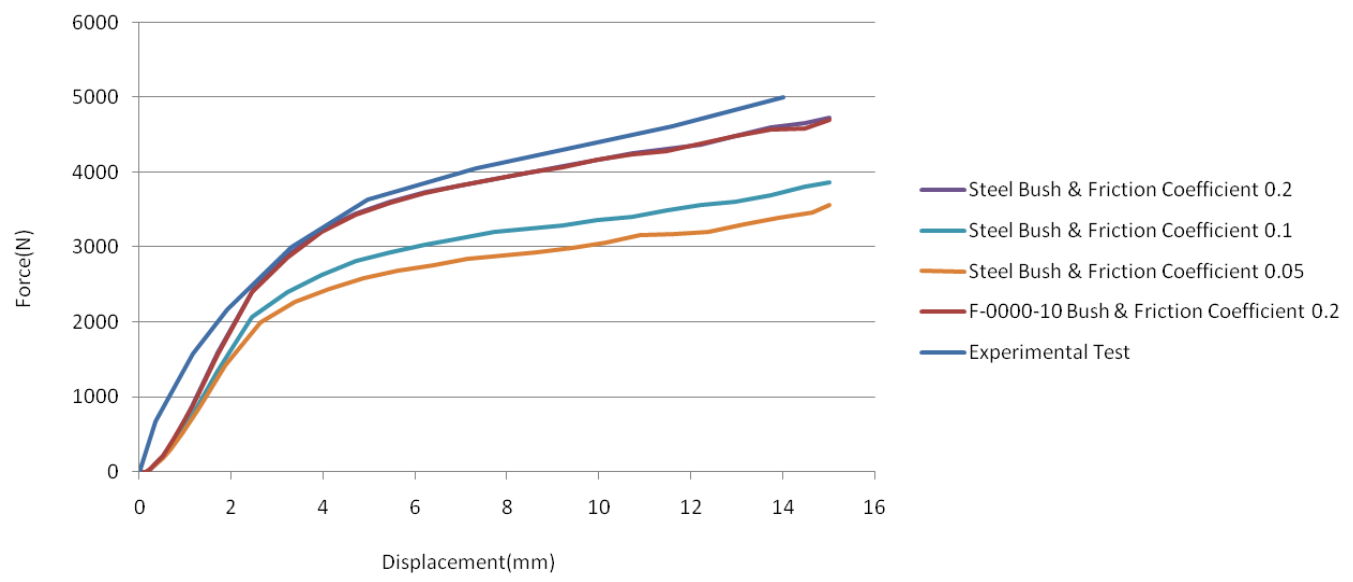

Figure 20. Direction $\mathrm{Z}$ force displacement curves according to simulation parameters.

\subsection{Phase- 2}

Geometrical data of 3D scan were used for calculations of this phase. One parameter was kept variable in order to see the effect of parameters on force-displacement. 
Friction Coefficient and Bush Material Effects for Z-Direction Loading

In Figure 21, the force-displacement results were shown for various friction coefficients. According to results, it was observed according to results that friction coefficients cause various frictional forces in the hinge system. Thus, results depend on the friction coefficient. In addition to the same results, it was observed that steel and F-0000-10 have coincident force-displacement curves. Therefore, it is interpreted that bush material does not have a significant impact on test results.

Unlike phase 1, it was observed that the force-displacement curve shows convergence at the beginning and the end. Also simulation model shows a $6.24 \%$ error value by using parameters which are the geometry of 3D scan, 0.2 friction coefficient, and bush material. This value is the smallest error value among other settings, and maximum and minimum error values are $6.24 \%, 25.23 \%$. Other error values are indicated in Table 2.

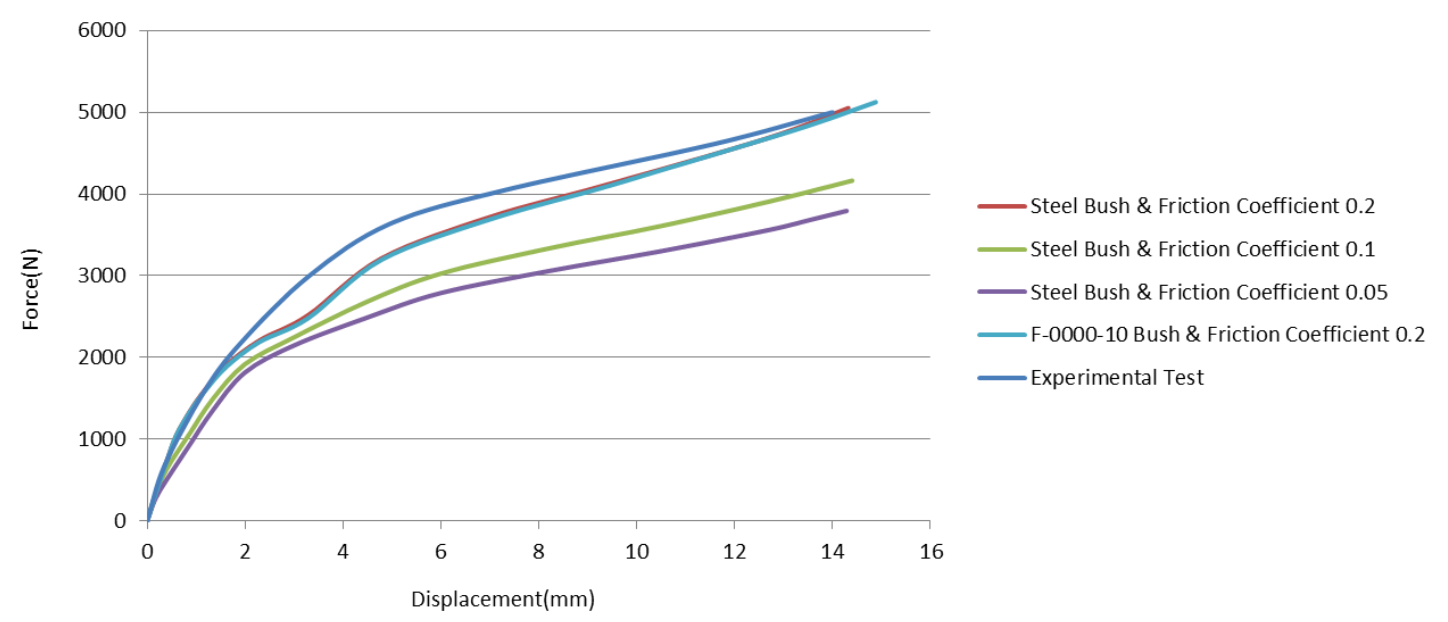

Figure 21. Direction of $Z$ force-displacement curves according to simulation parameters.

Table 2. Error values of force-displacement curves according to experimental tests.

\begin{tabular}{|c|c|c|c|c|c|c|c|}
\hline \multirow{2}{*}{$\begin{array}{l}\text { Simulation } \\
\text { No }\end{array}$} & \multirow{2}{*}{$\begin{array}{c}\text { UNECE R11 } \\
\text { Acceptance Criteria }\end{array}$} & \multicolumn{3}{|c|}{ Simulation Parameters } & \multicolumn{2}{|c|}{ Results (mm) } & \multirow[b]{2}{*}{ Error $(\%)$} \\
\hline & & Geometry & $\begin{array}{l}\text { Friction } \\
\text { Coefficient }\end{array}$ & Bush Material & Simulation & Experimental & \\
\hline 1 & \multirow{8}{*}{$\begin{array}{l}\text { No Separation at } \\
\text { Hinge Leaves } \\
\text { Under Required } \\
\text { Effort }\end{array}$} & Perfect Geometrical Data & 0.2 & Linear Steel & $\begin{array}{c}12.959 \\
\text { (No Separation) }\end{array}$ & \multirow{8}{*}{$\begin{array}{c}11.589 \\
\text { (No Separation) }\end{array}$} & 10.57 \\
\hline 2 & & Perfect Geometrical Data & 0.1 & Linear Steel & $\begin{array}{c}16.5 \\
\text { (No Separation) } \\
\end{array}$ & & 29.76 \\
\hline 3 & & Perfect Geometrical Data & 0.05 & Linear Steel & $\begin{array}{c}17.1 \\
\text { (No Separation) } \\
\end{array}$ & & 32.22 \\
\hline 4 & & Perfect Geometrical Data & 0.2 & F-0000-10 & $\begin{array}{c}10.85 \\
\text { (No Separation) }\end{array}$ & & 6.81 \\
\hline 5 & & 3D Scan & 0.2 & Linear Steel & $\begin{array}{c}8.31 \\
\text { (No Separation) } \\
\end{array}$ & & 8.31 \\
\hline 6 & & 3D Scan & 0.1 & Linear Steel & $\begin{array}{c}22.74 \\
\text { (No Separation) }\end{array}$ & & 22.74 \\
\hline 7 & & 3D Scan & 0.05 & Linear Steel & $\begin{array}{c}25.23 \\
\text { (No Separation) }\end{array}$ & & 25.23 \\
\hline 8 & & 3D Scan & 0.2 & F-0000-10 & $\begin{array}{c}6.24 \\
\text { (No Separation) }\end{array}$ & & 6.24 \\
\hline
\end{tabular}




\section{Conclusions}

Force-displacement curves of simulations and experiments were compared. The compliance of force-displacement curves of simulations and experiments are indicated as a percentage of errors in Table 2. Error values show that the deformation at simulation coincides with the experimental test results. The error values from 0 to 100 are the rating that shows the divergence ratio between the simulation models and experimental tests.

In this study, the effects of various simulation parameters were observed for the test at the $\mathrm{Z}$ direction in accordance with UNECE R11. During calculations, one parameter was kept variable and the effects of each one were inspected separately by comparing force-displacement curves. In addition, error values were calculated according to displacements, which provide the required force at regulation. It is observed from the results that realistic geometrical data has a big impact on force-displacement curves for simulations in the $\mathrm{Z}$ direction. In addition, bush material shows no big impact at simulations.

As a result of the study, it is observed that the correlation was achieved with 0.2 friction coefficient, bush material, and geometrical differences. These parameters were shared in order to use them for accurate correlation studies of hinge simulations with shorter times. In addition, the correlation steps of the simulation are shown during the study as a guide for the industry. If the correlation is established poorly with friction coefficient and bush material, the geometrical difference can be considered in simulations. This approach leads readers to have faster and cheaper correlations.

The study was conducted for only a $Z$ direction. As a future study, these parameters may be inspected according to other loading directions ( $X$ and $Y$ directions) in the regulation. In addition, the FE model, it may be improved by adding a fracture model for more precise crack estimations.

Author Contributions: O.E. conducted the experiment, O.E. and H.G.Ö. performed the tensile test on dog bone specimen. O.E. realized FE analysis. O.E. wrote and H.G.Ö. supervised the manuscript.

Funding: This research received no external funding.

Conflicts of Interest: The authors declare no conflict of interest.

\section{References}

1. Dogan, S.; Guven, C.; Karpat, F.; Dogan, O.; Yilmaz, T.G. Experimental Verification and Finite Element Analysis of Automotive Door Hinge. In Proceedings of the ASME 2014 International Mechanical Engineering Congress and Exposition, Montreal, QC, Canada, 14-20 November 2014. [CrossRef]

2. More, N.D.; Jadhav, T.A. Stress Analysis and Optimization of Car Door Hinge. Available online: http: //www.ierjournal.org/mit.php (accessed on 12 October 2018).

3. United Nations Economic Commission for Europe (UNECE). Available online: https:/ /www.unece.org/ fileadmin/DAM/trans/main/wp29/wp29regs/2013/R011r2e.pdf (accessed on 9 October 2018).

4. Tufekci, M.; Yılmaz, T.G.; Yüce, C.; Dogan, O.; Karpat, F. Otomobil kapi mentesesinin bilgisayar destekli tasarimi, Analizi ve Doğrulanmasl; Otomotiv ve Yan Sanayi Sempozyumu ve Sergisi: İstanbul, Türkiye, 2015.

5. Tufekci, M.; Karpat, F.; Yuce, C.; Dogan, O.; Yilmaz, T.G.; Kaya, N. Design optimization of aluminum hinge parts for lightweight vehicles: Performance, durability and manufacturability. Int. J. Mech. Prod. Eng. 2015, $3,6-13$.

6. Yılmaz, T.G.; Tufekci, M.; Karpat, F. A study of lightweight door hinges of commercial vehicles using aluminum instead of steel for sustainable transportation. Sustainability 2017, 9, 1661. [CrossRef]

7. Bayraktar, M.; Bilyaz, H.; Demir, C. Kinematic, kinetic and fatigue analyses of cup hinge with brake. Sak. Univ. J. Sci. 2018, 2. [CrossRef]

8. Toan, N.D.; Seogou, C.; Junyoung, P.; Yeongsung, S.; Youngsuk, K. Finite element method simulations to improve press formability of door hinge. J. Mater. Eng. Perform. 2008, 18, 1005-1011. [CrossRef]

9. Darwish, S.; Hussein, H.M.A.; Gemeal, A. Numerical study of automotive doors. Int. J. Eng. Technol. 2012, 12, 82-92.

10. Turna, S.. Analysis of True Stress Constitutive Equations; Sakarya University: Sakarya, Turkey, 2008. 
11. Metal Powder Industries Federation Standard 35-SP. Available online: https:/ / www.mpif.org/News/TabID/ 164/ArtMID/586/ArticleID/123/New-MPIF-Standad-35-Materials-Standard-Released.aspx (accessed on 8 May 2018).

12. Ansys Mechanical Plasticity Material Model User Guide. Available online: https://www.sharcnet.ca/ Software/Ansys/15.0.7/en-us/help/wb_sim/ds_plasticity.html (accessed on 8 March 2018).

13. Ansys Mechanical Contact Definition User Guide. Available online: https://www.sharcnet.ca/Software/ Ansys/16.2.3/en-us/help/wb_sim/ds_Contact_Definition.html (accessed on 1 October 2018).

(C) 2019 by the authors. Licensee MDPI, Basel, Switzerland. This article is an open access article distributed under the terms and conditions of the Creative Commons Attribution (CC BY) license (http:/ / creativecommons.org/licenses/by/4.0/). 